\title{
Organizational culture and knowledge cycle in the SMES of the tourist sector of the department of Caldas, Colombia
}

\author{
Cultura organizacional y ciclo del conocimiento en las PYMES del sector turístico \\ del Departamento de Caldas, Colombia
}

\author{
C. E. Marulanda-Echeverry ; A. P. Castaño-Vélez iD ; M. H. Mejía-Salazar iD \\ DOI: https://doi.org/10.22517/23447214.24507 \\ Artículo de investigación científica y tecnológica
}

\begin{abstract}
This article presents the results of a research that aims to determine the state of advancement of the life cycle of organizational knowledge related to the organizational culture in the SMEs of the tourism sector in the Department of Caldas, Colombia (part of the Eje Cafeteria region of Colombia). From a qualitative research, with a descriptive and correlational study, an evaluation model was applied in the SMEs of the tourism sector of the Department of Caldas (87\% valued), from which it was found the consolidation of an organizational culture for the development of the life cycle of knowledge in the SMEs evaluated. With these results, it is expected to deepen the dynamics of business knowledge management and propose strategies that help improve processes and generate social wealth.
\end{abstract}

Index Terms - Knowledge management, life cycle, organizational culture, SMEs, tourism.

Resumen- En este artículo se presentan los resultados de una investigación que tiene como objetivo determinar el estado de avance del ciclo de vida del conocimiento organizacional relacionado con la cultura organizacional en las PYMES del sector turístico del Departamento de Caldas, Colombia (parte de la región del Eje Cafetero colombiano). A partir de una investigación cualitativa, con un estudio de tipo descriptivo y correlacional, se aplicó un modelo de evaluación en las PYMES del sector turismo del Departamento de Caldas (87\% valorado), a partir del cual se encontró la consolidación de una cultura organizacional para el desarrollo del ciclo de vida del conocimiento en las PYMES evaluadas. Con estos resultados se espera profundizar en la dinámica de gestión del conocimiento empresarial y proponer estrategias que ayuden a mejorar los procesos y a generar riqueza social.

Palabras claves - Gestión del conocimiento, ciclo de vida, cultura organizacional, PYMES, turismo.

This manuscript was sent on October 21, 2020 and accepted on June 05,

\section{INTRODUCTION}

$\mathrm{T}$ ODAY'S world decks uncertain and complex paths in the business relationship and society, which face difficulties in commercial mediation: For companies, it is clear that they must be prepared to face various dynamics and developments that necessarily require the application of methods, methodologies, techniques or tools that make possible greater production, greater profitability and greater efficiency in relation to the optimization of their resources and a reduction in costs.

In this sense, knowledge management (KM) appears as the solution, as a key factor that makes the knowledge of individuals and social groups become profitability and also makes it possible to have a differentiating advantage of a company compared to its competition.

In this context, knowledge becomes a differential factor of all organizations, whether public or private. Organizations in the age of knowledge are in a constant process of change, and the valuation of intellectual capital and intangible assets is an imperative issue in this new scenario. The management, evaluation, and creation of knowledge, as well as stocks and intangible flows, are of vital importance for organizations. Wealth and well-being previously assessed, quantified, and measured by physical capital assets are measured in terms of intangibles, with knowledge created, managed, shared, transferred, and retained within organizations.

$\mathrm{KM}$ occupies an increasingly important role in the economy, assuming factors of production processes more important than land, capital, and labor. KM is a complex and multifaceted phenomenon, under a controversial concept whose expression, although widely used, presents different emphases, approaches, and interfaces, which deserve a thorough, meticulous and articulated analysis [1]. 
The tourism industry in the Department of Caldas is important because of the benefits it brings and because of its role as a commercial activity that creates demand and allows other industries to grow. Tourism not only contributes to more economic activities, but also generates more employment, income and plays an important role in local and territorial development. Hence the importance of assessing the state of knowledge management in companies in this sector and region and establishing improvement strategies.

\section{Metodology}

[2], cited by [3] developed a KM evaluation model, from the general systems theory, which is characterized by its holistic and integrating perspective and from a process management perspective, which was validated in the SMEs tourism operators of the Caldas Department of Colombia and it was possible to define a basic taxonomy as follows: we start from four dimensions, with their respective categories, as they are: This model can be seen in Fig. 1. The model is based on four dimensions, with their respective categories: organizational culture, information and communication technologies, IT, and the knowledge life cycle; communities of practice, containing the categories personal competencies and social relations; intensive use of knowledge, including the categories missionary processes, strategic processes, and support processes; and the organizational dimension, which includes the categories structure and results of SMEs.

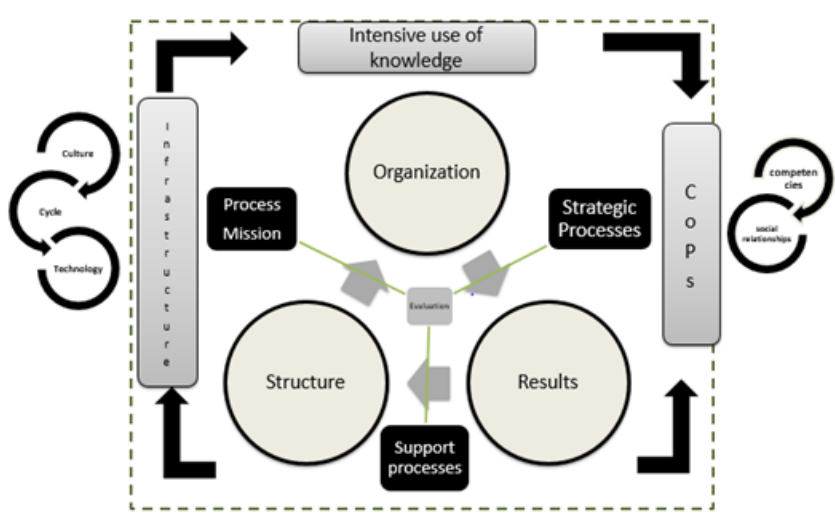

Fig. 1. Evaluation model.

The model was applied to SMEs in the tourism sector of the Department of Caldas, which according to, [4], cited by [3] is characterized by:

There are a total of 424 tourist service providers in the Department of Caldas, of which $67 \%$ are gastronomic establishments and bars, $21 \%$ accommodation and lodging establishments, $5 \%$ transport companies, $5 \%$ tourist guides and the remaining $2 \%$ travel agencies and tourism.

$73 \%$ are registered with the [4], Caldas and only $22 \%$ have the National Tourism Registry - RNT. These data, and especially the second, are an issue that the government should promote and tourism service providers should understand the importance of having such a registry. This serves as a mechanism of identification and, having it, is synonymous with legality, security and quality in their services. Respecting and following sectorial technical norms are essential if the tourism sector is to be a world-class sector.

$84 \%$ of tourist service providers do not speak a second language, which is quite a high and worrying figure, especially in the context of globalization, free trade agreements and the declaration of the Cultural Landscape Coffee -PCC as cultural heritage of humanity by UNESCO.

There are weaknesses in the technical standards of infrastructure, management and customer service that tourism service providers must meet to enter the quality standards at national and international levels.

Now, according to [3], to the kind of scope, the results are part of qualitative research, as well as a type of confirmatory and

correlational study, from the construction of the model and its validation in the SMEs of the touristic sector of Caldas' Department, which is composed of four dimensions of KM and IC. The scale of measurement was Likert, with a range of 1 to 5, where: a disagreement or not carried out (1), partially carried out (2), carried out in time intervals (3), carried out regularly (4), and carried out completely (5). View table I.

TABLE I.

CATEGORIES AND VARIABLES OF EVALUATION.

\begin{tabular}{|c|c|c|}
\hline Dimensions & Categories & Variable \\
\hline \multirow[t]{12}{*}{ Infrastructure } & \multirow[t]{5}{*}{ Km life cycle } & Identify \\
\hline & & Generate \\
\hline & & Retain \\
\hline & & Share \\
\hline & & Apply \\
\hline & \multirow[t]{4}{*}{ Digital technologies } & Fundamentals \\
\hline & & Methods \\
\hline & & Knowledge \\
\hline & & Technologies \\
\hline & \multirow{3}{*}{$\begin{array}{l}\text { Organizational } \\
\text { culture }\end{array}$} & People \\
\hline & & Storytelling \\
\hline & & Workplace \\
\hline \multirow{9}{*}{$\begin{array}{l}\text { Knowledge- } \\
\text { intensive use }\end{array}$} & \multirow[t]{2}{*}{ Strategic processes } & Planning \\
\hline & & $\begin{array}{l}\text { Information and } \\
\text { communication }\end{array}$ \\
\hline & Core processes & Service Delivery \\
\hline & \multirow[t]{6}{*}{ Support processes } & $\begin{array}{l}\text { Financial } \\
\text { Management }\end{array}$ \\
\hline & & $\begin{array}{l}\text { Commercialization } \\
\text { and marketing }\end{array}$ \\
\hline & & Technology \\
\hline & & Management \\
\hline & & Legal management \\
\hline & & $\begin{array}{l}\text { Stakeholder } \\
\text { management }\end{array}$ \\
\hline \multirow{3}{*}{$\begin{array}{l}\text { Communities of } \\
\text { practice }\end{array}$} & \multirow[t]{2}{*}{ Personal skills } & Leadership \\
\hline & & Creative Potential \\
\hline & Social Relationships & Communication \\
\hline
\end{tabular}




\begin{tabular}{|c|c|c|}
\hline & & Teamwork \\
\hline \multirow[t]{12}{*}{ Organization } & \multirow[t]{7}{*}{ Structure } & Type of business \\
\hline & & Number of \\
\hline & & Employees \\
\hline & & Experience \\
\hline & & Training \\
\hline & & Age \\
\hline & & IT Tools \\
\hline & \multirow[t]{5}{*}{ Outcomes } & Direction \\
\hline & & Loyalty \\
\hline & & Agreements \\
\hline & & Social \\
\hline & & Responsibility \\
\hline
\end{tabular}

[2], explain the first three dimensions; in the infrastructure dimension the following categories are considered:

KM life cycle: understood as a continuous process that makes it possible for knowledge to be transversal to each one of the organizational processes.

Digital technologies: understood as fundamental tools for $\mathrm{KM}$ that are used pervasively in organizations and therefore qualify as a natural means for the knowledge flow.

Organizational culture: understood as the set of habits, rituals, regulations, and ways of acting of an organization that serves as a facilitator of the relationship between staff and organizational knowledge, and determines that knowledge belongs to the organization and remains under individuals and groups control.

The knowledge-intensive dimension includes the following categories:

Strategic processes: are those that support the organizational strategy, which involves the management of the entity, in terms of decision making that affect the other processes of the organization.

Core processes: are those that combine and transform resources to obtain the product or provide the service according to the customer's requirements.

Support processes: are those that provide people and the physical and financial resources required for the remaining processes, and according to the requirements of their internal customers.

In terms of the communities of practice dimension, the categories considered are as follows:

Personal competencies: refer to the set of knowledge, attitudes, skills, and concerns of people in an organization that makes it competitive, since they cannot be easily replicated.

Social relations: are those that are generated and built from the values of cooperation and organizational interaction, and that is necessary to share and apply knowledge.

This article's authors added the following categories to the evaluation model about IC:

Structure: understood as the support of SMEs related to the basic characteristics of the employees who work in them.

Outcomes: are those related to customer and stakeholder orientation.

The economic sector of this study in which the model presented was applied and contrasted corresponds to SMEs in the touristic sector of the Caldas department (Colombia). To obtain the data, we proceeded to review the number of SMEs, which were identified as touristic operators, which allowed us to identify a population of 70 companies, of which 61 gave an affirmative response to participation in the study $(\mathrm{n}=87.14 \%$ of the population).

To validate the model, the relational and underlying structures were identified and a multivariate normality analysis was carried out, to recognize the data present normal structures (C.R. $\leq 2.0$ ), followed by a Cronbach alpha analysis, which served to measure the reliability of the measurement scale. The criterion followed was to consider a high degree of correlation $(\rho \geq .7)$ and reliability $(\alpha \geq .7)$. Subsequently, an exploratory factorial analysis was used to evaluate the existence of a common variance that explains the underlying existence of each of the dimensions and that these, when integrated, corresponded to the domain to be constituted.

\section{State Of ART}

Knowledge management can be understood as a continuous flow from data to information and from information to knowledge. In organizations, knowledge is found in organizational routines, processes, practices, and business rules, as well as in documents or databases. Business relevant knowledge includes facts, opinions, ideas, theories, principles, and models. In this way, knowledge is a dynamic human process of justifying personal belief in search of the truth. That is, when it comes to knowledge, unlike information, it also involves beliefs and commitments. Knowledge, unlike information, is action. Knowledge, unlike information, is about the meaning and depends on specific contexts and is relational [5].

In this sense [6], they suggest evaluating knowledge on three levels: knowledge retention, application, and problem-solving. (1) Knowledge retention: The first level describes the recall and recognition of facts, patterns, processes, classification, criteria, or categories. This level is characterized by passivity and a limited ability to describe it. (2) Understanding: The second level covers understanding and application. Understanding is the ability to recognize simple correlations, as well as the independent ability to explain. Application is the ability to apply knowledge in new situations. (3) Problem-solving: This level comprises analysis, synthesis, and evaluation. An analysis is the ability to break down complex problems into fundamental elements and recognize the relationships between these elements. Synthesis is the ability to combine fundamental elements of a new system by developing a new structure. Evaluation is the ability to judge, including internal and external validity based on a set of criteria.

\section{A. Knowledge management}

There is broad agreement among researchers, entrepreneurs, and managers that knowledge is one of the strategic intangible 
assets for the organization. It is necessary to develop and manage the knowledge that one has, achieving that the information is converted into actions that create value. This requires not only the incorporation of collaborative technological platforms, good training programs, development of efficient processes, or corporate manuals, but it also requires reviewing and making changes in attitudes and cultural changes that allow and enhance the acquisition, learning, and broad and collaborative use of this knowledge. Organizational knowledge is key to the success of strategies, and knowledge management is a methodology that allows collaboration in the administration and development of knowledge and the development of the economy and productivity of companies [5].

[7] they explain that knowledge is a unique key strategic resource and allows companies to compete in a dynamic environment. Companies are continuously evolving through the production and use of knowledge and it becomes imperative for top management to value knowledge, create and maintain knowledge sharing.

[8] they explain that $\mathrm{KM}$ in organizations enables the creation and sharing of knowledge that results in improvements in productivity, innovation, competitiveness, and relationships among people, in addition to creating learning, problemsolving, and effective decision making.

[9] define $\mathrm{KM}$ as the management function that creates or localizes knowledge, manages the flow of knowledge within organizations, and ensures that knowledge is used effectively and efficiently for the long-term benefit of the organization. $\mathrm{KM}$ is used to describe the processes that obtain and use knowledge within and outside the organization in ways that can lead to the achievement of organizational objectives and that seek to improve productivity, create a sustainable competitive advantage, and create and protect a company's intangible assets.

Meanwhile [10] they define KM as the successive activities aimed at developing mechanisms for creating, capturing, storing, transmitting and interpreting tacit and explicit knowledge, allowing the use and utilization of the learning that takes place in individuals and teams, in order to achieve organizational objectives, meet needs, develop new opportunities and generate sustainable competitive advantages. In this sense [11], they refer to the application of collective knowledge to achieve the goals and objectives of an organization. It is a process that encompasses different activities, such as the capture, sharing, storage, retrieval and reuse of knowledge

$\mathrm{KM}$ involves the process of creating, sharing, and using knowledge and information in an organization and becomes necessary to facilitate the process of converting large amounts of data into knowledge [12]. The KM process is subdivided into 3 different phases: 1) the creation phase, in which knowledge is acquired and validated, 2) the storage phase, in which knowledge is retained and organized, and 3) the transfer phase, in which various actors exchange and share knowledge [13].

They expand [14], considering that KM allows for the search, acquisition, analysis, and classification of knowledge from various information sources. Giving information to human and computer networks once the knowledge is usable is ready to be consulted; negotiating about the integration or exclusion of knowledge in the system; explaining the quality and reliability related to knowledge integration and learning progress throughout the knowledge management process

They explain [15], that KM is one of the crucial assets in organizations, as it enables organizational development and creativity. The proper use of KM is considered an important issue in achieving high effectiveness and efficiency. In this sense, knowledge acquisition refers to the process that uses and captures new knowledge; knowledge sharing refers to the process of disseminating knowledge among all individuals involved in the practices of a specific task, and; knowledge application is defined as the process that enables the organization to easily access knowledge through storage and retrieval practices as well as the sharing of knowledge produced in the acquisition and dissemination stages for application in various processes.

\section{B. Life cycle to manage knowledge}

They align [16], [17] and [18] Lee and Choi (2003) which establish the following activities for the knowledge cycle: creation and acquisition, organisation and retention, sharing and distribution and application of knowledge. Creation and acquisition includes construction, collection, generation, creation, acquisition and capture activities [19]. Organization and retention, explain [20], must start from the relevance and value of knowledge. It is necessary to determine the degree of confidence in that knowledge, consolidate useful knowledge and eliminate redundant knowledge, determine how to develop and create knowledge that is not there, determine the degree of uncertainty of unforeseen knowledge, identify and propose alternatives to contradictory knowledge. As for sharing and distributing, in a learning oriented organization knowledge is disseminated quickly within the organization, knowledge is transferred both horizontally and vertically (with suppliers, clients, or collaborative institutes).

In its application, value is generated by incorporating knowledge into products and services, adopting best practices throughout the organization. "The processes of assimilation and application are situated in a learning context, which is related to mechanisms of assimilation and internalization of information that is communicated, transmitted and shared, either tacitly or explicitly" [21]. Considering these phases, [22] make a revision and determine an evident consensus with four common phases that cover the life cycle of KM: (1) acquisition / creation / generation, (2) retention / storage / capture, (3) sharing / transfer / dissemination and (4) application / utilization 
/ use.

Given the above, it is considered that the life cycle phases of KM should include inputs, processing, outputs, storage and application, within the framework of the use of various tools to make this possible. In this case, the life cycle is grouped into the following phases:

Identify knowledge: identification of existing knowledge is essential to support decision making. Useful benchmarks for this exercise are customer requirements, results of value-added processes and process steps. In order to encourage the reuse of existing knowledge, this identification step must often be done before creating new knowledge. Methods and tools that support this stage include, for example, systematic search strategies, mapping techniques, and the exchange of feedback ideas. All individuals in the enterprise must have access to the knowledge base and systems such as communities of practice, personal networks, organizational practices and routines can be used for this purpose.

Generate knowledge: is often the result of social interaction, through training, learning by doing, solving the joint solution or brainstorming. In an organization, innovation processes are typically to create new knowledge for products and services. Generation can take place within the research and development function, through the creation of expert groups. The generation of knowledge requires greater specialization than is necessary for the use of knowledge. It requires a coordinated effort of individual specialists possessing different types of knowledge and is accelerated by fostering synergistic interrelationships with individuals from diverse backgrounds. [23] propose the creation of knowledge through processes of conversion between tacit and explicit knowledge, which expands in quality and quantity, improving corporate performance. Creation is a continuous process. The key to knowledge creation lies in the way knowledge is mobilized and transformed by technology, making it possible to create new knowledge by searching for new tasks or finding knowledge from external sources.

Retain knowledge: knowledge can be retained in the team or organizational routines. Another way to ensure knowledge is institutionalization, such as so-called structural capital, processes and culture. The retention of explicit knowledge depends on supporting activities such as selection, organization or categorization, as well as updating and debugging content. The retained knowledge of the individual is developed through his observations, experiences and actions and implies a repository, which can be itself or an information system. Systems such as communities of practice, personal networks, organizational practices and routines can be used to retain knowledge. Although [24] argues that KM should encourage dialogue among individuals and not just point to repositories.

Knowledge sharing: knowledge can be added to databases or distributed through documents. But knowledge can be transferred from one person to another by direct interaction through collaboration, workshops, training, learning, among others. [25] state that it is the most appropriate expression and is used to describe the exchange of knowledge between people, with emphasis on the exchange of knowledge within groups and teams. It is argued that simple knowledge can be formally shared through scheduled meetings, training, conferences and formal discussions. [26] define it as the movement of knowledge from sender to receiver, the understanding of the knowledge transmitted and its integration with the existing knowledge in the mind of the receiver. Knowledge is often modified in the mind of the receiver. Knowledge transfer channels can be formal or informal, such as unscheduled meetings, informal meetings and coffee breaks. The latter promotes socialization and can be effective in small organizations that oppose wide dissemination [27].

Apply knowledge: the application of knowledge could uncover new gaps in knowledge, as well as the acquisition of new experiences that could represent new knowledge. One of the most popular forms of knowledge application is the adoption of best practices, although systems such as new business based on IT and processes can be used. It makes it accessible whenever necessary, from an active knowledge management approach and the integration of this process into your overall strategic management framework.

\section{Organizational Culture and Knowledge management}

[28] state that knowledge creation, corporate culture in an SME, its management systems, operating systems and resource management are the crucial sources of competitive advantage. According to [29], in the body of literature available on KM, the concept of "culture" has been used several times. This concept is presented primarily in terms such as "knowledgesharing culture" or "knowledge culture". Although other expressions such as "organizational culture", "organizational climate" or "national culture" were also proposed, "knowledge culture" is one of the specific branches of organizational culture. This indicates a way of life of the organization that uses people in the process of creating and exchanging information.

In this sense, [30] establishes that culture can be modified through specific management practices that have to do with strategic direction, personnel selection, rewards and recognition, employee deployment, support for the generation of ideas and teamwork to encourage innovative behaviour. In addition, the development of learning capacity within organisations with a socio-cultural climate for learning has to coexist with structures, systems and procedures. They complement [31] and [32] explaining that each organization has its own policies, practices and culture, which are not only technical, but also managerial and administrative. Some complementary elements of the culture would be: to take advantage of the experience of the employees, to share experiences with the clients and the rotation of work, dynamics of teams, communication, learning and sharing, process of 
documentation, process of KM and commitment, among others [33].

An organization's culture acts as a mediator of the relationship between staff and organizational knowledge. It determines that knowledge belongs to the organization and remains under the control of individuals and groups. The objectives set for KM in the organization, therefore, should take into account the norms and habits related to ownership and control of specific knowledge, in order to favor the transition of staff to organizational knowledge.

This is based, according to [29], on: that beliefs and values that are built from early childhood experiences and generally mature with experiences as adults. The leadership style applied to a particular work situation creates a climate in which people work. People's credibility within communities has a big impact on what to respond to and the quality of response and motivation. The latter can be given by coincidence, fear and greed, attractiveness of action choice, improvement (associated with a perceived improvement in power or personal or positional or promotional opportunity) and recognition.

[34] propose a methodology for the study of organisational culture, based on the Competing Values Framework (CVF) model. This model defines four types of culture, based on two dimensions:

The first dimension, stability versus flexibility, refers to whether the organization considers order and control (stability) or dynamism and discretion (flexibility) more important.

The second dimension raises two opposing values: whether the company has an internal orientation or has an external orientation. Combining the two competing values, the model distinguishes four types of culture: clan, adhocratic, hierarchical and market. Culture can be defined in terms of six traits that can help people recognize the cultural values of their organization, these are: (1) the dominant characteristics of the organization; (2) the leadership style and the approach that permeates the organization; (3) the management of employees or the style that characterizes how employees are treated; (4) the organizational link or mechanism that helps the organization stay united; (5) the strategic emphasis or areas that guide the organization's strategy; (6) the criterion of success, which refers to how success is defined in the organization.

The variables related to culture and that were considered for the results of the research project, the basis of this article are:

People: relates to personality traits, aptitudes and cognitive skills for KM.

Narrative: relates to creation traits and growth profile for KM.

Workplace: relates to physical space and organizational climate for KM.

\section{RESULtS}

In this framework the results of the analysis of the life cycle of knowledge related to: identify (ID), generate (GEN), retain (RET), share (COM) and apply (APL) and the analysis of organizational culture related to: people (PERSO), narrative (NARR) and workplace (SITIO), can be seen in Fig. 2.

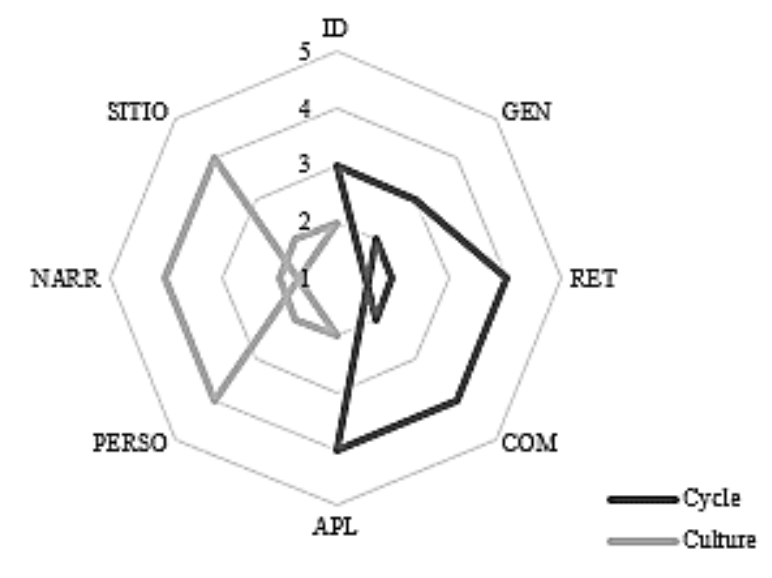

Fig. 2: Organizational cycle and culture

According to the rating scale, the evaluated variables of the knowledge life cycle related to: identify (ID), generate (GEN), yielded a rating of 3 , that is, carried out in time intervals, while the variables retain (RET), share (COM) and apply (APL) with 4 , that is, carried out regularly, which could be explained by the development that these companies are having from management and administration, which understands the importance of the application of the knowledge life cycle for their benefit.

However, concerning the evaluated variables of the organizational culture related to: people (PERSO), narrative (NARR) and workplace (SITIO), gave a rating of 4.0, ie made regularly, which could be explained by the development that these companies have had since the management and administration of them, product of high-level training presented by managers, directors or managers and their understanding of the importance of organizational culture for knowledge management.

The previous valuations in a framework of continuous improvement, directly related to processes of quality improvement of services and expansion of markets to customers more eager to live tourist experiences especially those around the cultural coffee country.

These results go in the same line of those found by: [35], who explain that knowledge is a mixture of contextual information, framed experience, expert experience and value that results in innovation and pristine experience. Cutting-edge knowledge is considered as organizational culture, skills, reputation, intuition and codified theory that influences human behavior and 
thinking. An effective and efficient organizational culture can stimulate knowledge management and exchange activities; in this sense, every organization must have a predominant culture in which trust, sociability and values stimulate the exchange of knowledge and interaction between staff. Knowledge creation takes place through participation and/or learning, new knowledge and/or market knowledge that are essential to update and reactivate knowledge, according to this, learning influences the amount of knowledge that can be applied to exploitation opportunities, and the knowledge created can be applied to new products, services or business processes, which leads to learning having an impact on knowledge creation processes and organizational performance [36].

Likewise, [37] they conclude that the starting point for knowledge is inside and outside the organization, based on customers, research and suppliers. The importance of KM is created by culture, infrastructure, and objectives. A corporate culture that is sensitive to knowledge is created by normative knowledge objectives and is a culture that makes possible the creation and exchange of knowledge.

[38] who found that organizational culture facilitates the improvement of knowledge exchange through people and technology, through the circulation of knowledge, in the framework of a cognitive process of conversion between tacit and explicit knowledge. Thus, the exchange of knowledge is a phenomenon of behavior, as are behaviors, values, norms and practices that influence the exchange of knowledge creation and its use.

[39] in addition to codified individual knowledge and skills, individuals in an efficient enterprise need to know how to respond effectively to maximize the quality and quantity of general goods and services provided. This requires an organization that can efficiently coordinate activities and incentivize some actions and penalize others to optimize the collective results of the organization.

[35], who explain that cutting-edge knowledge is also considered to be an organizational culture, skills, reputation, intuition, and codified theory that influences human behavior and thought. The knowledge-sharing behaviour of individuals is influenced by a number of factors, ranging from the provision of incentives and motivations to inspire exchange of knowledge, personal values and self-identity, trust, national culture, organisational resources such as space, time and access to people with knowledge in the field of education. Organisational culture refers to the softer aspects of human life and organisational behaviour. It includes issues of politics, selfperception, leadership and motivation. Knowledge sharing is likely to be influenced by various socio-psychological factors, such as incentives and personality characteristics as well as organizational and social culture [40].

[41], conclude that an organization must create a culture proportional to it in order to carry out knowledge management and act successfully on it. The weakness of the organizational culture prevents people from sharing their knowledge in order to maintain their personal power and efficiency. Thus, when its organizational culture and its dimensions and indices are not sufficiently known, an organization faces many problems, such as organizational opposition, lack of organizational cohesion, and increased performance in practice. Knowledge of organizational culture as an important need has allowed one of the priorities of managers' activities, as management can organise their activities in the short and long term. The culture of the organization influences knowledge management in four ways: The role played by the organizational culture on the identity of knowledge and its importance for the organization, management; the role of culture in creating relationships between people and the knowledge of an organization; the cultural patterns that identify how knowledge should be used in special situations and the processes of elaboration, legitimization and dissemination of knowledge in an organization.

[26] explain that culture affects behaviors that are related to knowledge, people, groups, organizations, organizations, etc., and also has a decisive influence in deciding when, where and with whom to exchange knowledge. The organizational culture is considered to be the most influential in knowledge management and organizational learning. Organizational culture could affect knowledge in four different ways: The culture that indicates the most important type of knowledge, the culture in interpersonal and organizational relations acts as a mediating variable, the culture sets the stage for social interaction (reciprocal relationship between members of an organization) and the culture formulates the processes necessary for the production and selection of modern knowledge.

Or as raised by [42], who conclude that the organization has to develop a culture for knowledge creation through the development of ways to encourage employees to share through the creation of incentives, as well as awareness of the positive values and influence that sharing has for the individual, groups and organization. Unlike knowledge creation, knowledge acquisition involves the pursuit, recognition and assimilation of potentially valuable knowledge, often from outside the organization. The culture of knowledge sharing allows the development of new knowledge, ideas, or products that can lead to the formation of creative initiatives. In other words, culturebased creativity is associated with people's ability to work in a knowledge-sharing culture.

However, the findings presented demonstrate the importance of organizational culture (with its variables, ID, GEN, RET, COM and APL) in the life cycle of knowledge (with its variables, PERSON, NARR and SITIO) in SMEs in the tourism sector of the Department of Caldas, however, it is important to analyze their relationship in these companies, as can be seen in table II.

TABLE II 


\section{CORRELATION ANALYSIS}

\begin{tabular}{|c|c|c|c|c|c|c|c|c|}
\hline & ID & GEN & RET & $\begin{array}{c}\mathrm{CO} \\
\mathrm{M}\end{array}$ & APL & $\begin{array}{c}\text { PERS } \\
\mathrm{O}\end{array}$ & $\begin{array}{c}\text { NAR } \\
\text { R }\end{array}$ & $\begin{array}{c}\text { SITI } \\
\mathrm{O}\end{array}$ \\
\hline ID & 1 & & & & & & & \\
\hline GEN & ,473* & & & & & & & \\
\hline RET & ,564* & ,493* & & & & & & \\
\hline COM & ,752* &, $532^{*}$ & ,694 & & & & & \\
\hline APL & ,714* &, $539^{*}$ &, $729^{*}$ & ,688 & & & & \\
\hline $\begin{array}{l}\text { PERS } \\
\text { O }\end{array}$ & ,645 &, $576^{*}$ & , $660^{*}$ &, $742^{*}$ & ,647* & & & \\
\hline NARR & ,733* &, $569^{*}$ &, $652^{*}$ &, $770^{*}$ &, $688^{*}$ &, $816^{* *}$ & & \\
\hline SITIO & ,601* & ,494* & ,686* & ,765 & ,636 &, $741^{* *}$ &, $689^{* *}$ & 1 \\
\hline
\end{tabular}

**.nivel 0,01 (2).

The results of the correlation analysis show that there is a significant correlation between the organizational culture and the life cycle of knowledge in the SMEs of the tourism sector of the department of Caldas, results that follow the same line as those presented by [43], which concludes that in order to build a knowledge network that supports strategic decision-making it is crucial to consider the alignment of external and internal organizational factors. These factors include organizational strategy, organizational culture, organizational capacity, and knowledge management infrastructure. Likewise the findings of [44], who conclude that knowledge management is not only a process of acquisition, integration, storage, exchange and transfer of knowledge, application, innovation, etc., is the result of the relationship with strategy and leadership, organizational culture, performance evaluation and technical information.

And those found by [45], who conclude that knowledge management requires factors such as trust, organizational culture and rewards to increase knowledge sharing. In addition, knowledge management relies on the contributions of collaborators and the decentralization of knowledge holders. The key factors affecting knowledge transfer are: culture, absorptive capacity, research and development (R\&D) intensity and structure, strategy, size and trust. And what was found by [46], who explain that Organizational culture is one of those that facilitates knowledge management. Knowledge facilitators are influential factors that consistently improve knowledge through some activities or practices of the knowledge management process.

\section{CONCLUSIONS}

The central government of Colombia has been weaving initiatives for the development of the tourism sector and in this sense some support has been given for the development of the sector, which is projected as one of the most important in the country, for its potential in all areas of tourism, sustainably exploiting cultural, biological and social diversity, among others that are available. In this dynamic, the evaluated companies are part of the coffee cultural landscape and they have the hopes of development of the sector in what it is doing, in terms of offering more and better products and services to the national and international community.

The KM is the current key to organizational success and this is how the companies of the world have been recognizing it. In the case of the SMEs of the tourist sector of the Department of Caldas, it is observed in the findings that have been making processes that allow positioning the life cycle of knowledge as an important factor for its development. What could also be observed in terms of the organizational culture for knowledge management and in this sense, having personnel who understand the cultural dynamics implied by knowledge sharing is fundamental for the achievement of the objectives of these companies.

There is a direct relationship between the organizational culture and the life cycle of knowledge and it is clear that any initiative related to knowledge management cannot be supported solely by declaring it or by using various technological means or even some rewards for making knowledge management a concept that makes it possible to store information. It is clear that it is necessary to think integrally, holistically, so that from the organizational culture, with all the variables that accompany it, knowledge can be shared, it can be offered, it can be delivered and at the same time it can be converted into innovative ideas of services, products or processes.

\section{ACKNOWLEDGMENTS}

This work is part of the results of the research project entitled "Intellectual capital for the generation of value through knowledge management in companies in the tourism sector of the Department of Caldas", which was registered and funded by the Research office of the Universidad Nacional de ColombiaManizales and Vice-president of Research of Universidad de Caldas, the code Hermes 36752.

\section{REFERENCES}

[1] J. Rezende, A. Correia \& B. Gomes, «The intellectual capital and the creation of value in research units linked to the Brazilian Ministry of Science Technology and Innovation,» RAI Revista de Administração e Inovação, no $14, \quad$ pp. 199-215, 2017. https://doi.org/10.1016/j.rai.2017.03.010

[2] C. Marulanda, J. Giraldo \& H. Serna, «Modelo de evaluación de gestión del conocimiento para las pymes del sector de tecnologías de la información,» $A D$-minister, no 26, pp. 17 - 39., 2015. doi: 10.17230/administer.26.2.

[3] C. Marulanda, M. López \& F. López, La Cultura Organizacional y las Competencias para la Gestión del Conocimiento en las Pequeñas y Medianas Empresas (PYMEs) de Colombia. Inf. tecnol., Vol. 27, no 6, 2016. http://dx.doi.org/10.4067/S0718-07642016000600002.

[4] M. Cámara de comercio, «Cámara de comercio de Manizales,» 2407 2014. [En línea]. Available: http://www.ccmpc.org.co/ccm/noticias/?Noti_Id=P1C2BqY\%2BpUvS YWLVBhnr4g\%3D\%3D.

[5] D. Liberona \& M. Ruiz, Análisis de la implementación de programas de gestión del conocimiento en las empresas chilenas. Estudios gerenciales Vol. 29, pp. 151-160, 2013. https://doi.org/10.1016/j.estger.2013.05.003 
[6] S. A. Schenkl, D. M. Schmidt, D. Schockenhoff, \& M. Maurer, Knowledge evaluation for PSS providers. Procedia CIRP, Vol. 16, pp. 86-91, 2014. https://doi.org/10.1016/j.procir.2014.01.011.

[7] S. K. Singh, S. Gupta, D. Busso \& S. Kamboj, Top management knowledge value, knowledge sharing practices, open innovation and organizational performance. Journal of Business Research. 2019. https://doi.org/10.1016/j.jbusres.2019.04.040.

[8] DGJ Dei \& TB, Van Der Walt, Prácticas de gestión del conocimiento en las universidades: el papel de las comunidades de práctica. Abierto de Ciencias Sociales y Humanidades , Vol. 2, no 1, 2020. https://doi.org/10.1016/j.ssaho.2020.100025

[9] E. Ode \& R. Ayavoo, El papel mediador de la aplicación del conocimiento en la relación entre las prácticas de gestión del conocimiento y la innovación empresarial. Revista de innovación y conocimiento , Vol. 5 no 3, pp. 210-218, 2020. https://doi.org/10.1016/j.jik.2019.08.002

[10] L. Tovar, \& B. Muro, La gestión del conocimiento en la industria automovilística. Estudios gerenciales, Vol. 23, no 102, pp. 83-100, 2007. https://doi.org/10.1016/S0123-5923(07)70003-7

[11] H. Wang \& X. Meng, Transformation from IT-based knowledge management into BIM-supported knowledge management: A literature review. Expert Systems with Applications, no 121, pp. 170-187, 2019. https://doi.org/10.1016/j.eswa.2018.12.017

[12] D. G. Schniederjans, C. Curado \& M. Khalajhedayati, Supply chain digitisation trends: An integration of knowledge management. International Journal of Production Economics, no. 220, pp. 107439, 2020. https://doi.org/10.1016/j.ijpe.2019.07.012.

[13] R. Cerchione \& E. Esposito, Using knowledge management systems: A taxonomy of SME strategies. International Journal of Information Management, Vol. 37 no. 1, pp. 1551-1562, 2017. https://doi.org/10.1016/j.ijinfomgt.2016.10.007.

[14] D. Monticolo, I. Lahoud \& P. C. Barrios, OCEAN: A multi agent system dedicated to knowledge management. Journal of Industrial Information Integration, no. 17, pp. 100124, 2020. https://doi.org/10.1016/j.jii.2019.100124.

[15] M. Al-Emran, V. Mezhuyev \& A. Kamaludin, Towards a conceptual model for examining the impact of knowledge management factors on mobile learning acceptance. Technology in Society, pp. 101247, 2020. https://doi.org/10.1016/j.techsoc.2020.101247.

[16] R. Grant, Contemporary Strategy Analysis: Concepts, Techniques, applications, Boston: Blackwellpublishers, 2002.

[17] H. Lee \& B. Choi, «Knowledge Management Enablers, Processes, and Organizational Performance: An Integrative View and Empirical Examination,» Journal of Management information System, pp. 179228, 2003. https://doi.org/10.1080/07421222.2003.11045756.

[18] Centro Europeo de Normas, European Guide to good practice in Knowledge management, Bruselas: European Committee for Standardization, 2004.

[19] K. Yamada \& V. Kimala, «Acquiring Knowledge from Decision Tables for Evidential Reasoning,» Advances in Soft Computing Springer, pp. 407-416, 2010. DOI: 10.1007/978-3-642-11960-6_38.

[20] J. Rezende \& J. Souza, «Using Knowledge Management Techniques to Improve the Learning Process through the Exchange of Knowledge Chains,» de 11th International Conference on Computer Supported Cooperative Work in Design, Melbourne, 2007. DOI: 10.1109/CSCWD.2007.4281518

[21] R. Plaza \& N. Gonzalez, La Gestión del Conocimiento Organizativo. Dinámicas de agregación de valor en la organización. Revista de Economia Industrial, pp. 41-54, 2005.

[22] D. Sedera \& G. G. Gable, «Knowledge Management Competence for Enterprise System Success,» Journal of Strategic Information Systems, no. 296-306, pp. 296-306, 2010. https://doi.org/10.1016/j.jsis.2010.10.001.

[23] C. Lopez-Nicolas \& P. Soto-Acosta, Analyzing ICT adoption and use effects on knowledge creation: An empirical investigation in SMEs. International Journal of Information Management, pp. 521-528, 2010. https://doi.org/10.1016/j.ijinfomgt.2010.03.004.
[24] K. Desouza, Barriers to Effective Use of Knowledge Management Systems in Software Engineering. Communications of the ACM, Vol 46, no. 1, pp. 99-101, 2003. https://doi.org/10.1145/602421.602458.

[25] S. Ryan y R. V. O'Connor, «Acquiring and Sharing Tacit Knowledge in Software Development Teams: An Empirical Study,» Information and Software Technology, pp. 1-24, 2013. https://doi.org/10.1016/j.infsof.2013.02.013.

[26] S. Dorairaj, J. Noble \& M. Petra, «Knowledge Management in Distributed Agile Software Development,» 2012. DOI: 10.1109/Agile.2012.17.

[27] M. Alavi \& D. E. Leidner, «Knowledge Management Systems: Issues, Challenges and Benefits,» Communications of AIS, vol. 1, no. 2, pp. 137, 1999. DOI: 10.17705/1CAIS.00107.

[28] S.-T. Li \& M.-H. Tsai, «A dynamic taxonomy formanaging knowledge assets,» Technovation, no 29, pp. 284-298, 2009. https://doi.org/10.1016/j.technovation.2008.10.002.

[29] M. Allameha, M. Zamani \& S. M. Reza-Davoodia, «The Relationship between Organizational Culture and Knowledge Management,» Procedia Computer Science, no. 3, pp. 1224-1236, 2011.

[30] T. Koc, «Organizational determinants of innovation capacity in software companies,» Computers \& Industrial Engineering, pp. 373385, 2007. https://doi.org/10.1016/j.cie.2007.05.003.

[31] I. Rus \& M. Lindvall, «Knowledge Management in Software Engineering,» IEEE Software, pp. 26-38, 2002.

[32] S. Basri \& R. O'Connor, «The Impact of Software Development Team Dynamics on the Knowledge Management Process,» 2012.

[33] A. Aurum, F. Daneshgar \& J. Ward, «Investigating Knowledge Management practices in software development organisations - An Australian experience,» Information and Software Technology, pp. 123, 2007. https://doi.org/10.1016/j.infsof.2007.05.005.

[34] K. Cameron \& R. Quinn, Diagnosing and Changing Organizational Culture., Addison- Wesley, Series on Organization., 1999.

[35] A. Abubakar, H. Elrehail, M. Alatailat \& A. Elci, «Knowledge management, decision-making style and organizational performance,» Journal of Innovation \& Knowledge, no. 4, pp. 104-114, 2019. https://doi.org/10.1016/j.jik.2017.07.003.

[36] M. Loon, «Knowledge management practice system: Theorising from an international meta-standard,» Journal of Business Research, no 94, pp. 432-441, 2019. https://doi.org/10.1016/j.jbusres.2017.11.022.

[37] O. Mahdi, I. Nassar \& M. Almsafir, «Knowledge management processes and sustainable competitive advantage: An empirical examination in private universities,» Journal of Business Research, no 94, pp. 320-334, 2019. https://doi.org/10.1016/j.jbusres.2018.02.013.

[38] O. Oyemomi, S. Liu, I. Neaga, H. Chen \& F. Nakpodia, «How cultural impact on knowledge sharing contributes to organizational performance: Using the fsQCA approach,» Journal of Business Research, no 94, pp. 313-319, 2019. https://doi.org/10.1016/j.jbusres.2018.02.027.

[39] M. Khan. Knowledge, skills and organizational capabilities for structural transformationStructural Change and Economic Dynamics, no. 48, pp. 47-52, 2019. https://doi.org/10.1016/j.strueco.2018.05.006

[40] M. Martinsons, R. M. Davison \& Q. Huang, «Strategic knowledge management failures in small professional service firms in China.,» International Journal of Information Management, no. 37, pp. 327-338, 2018. https://doi.org/10.1016/j.ijinfomgt.2017.04.003.

[41] G. Ahmady, A. Nikooravesh \& M. Mehrpour, «Effect of organizational culture on knowledge management based on Denison model,» Procedia - Social and Behavioral Sciences, no. 230, pp. 387-395, 2016. https://doi.org/10.1016/j.sbspro.2016.09.049.

[42] F. Torabi \& J. El-Den, «The impact of Knowledge Management on Organizational Productivity: A Case Study on Koosar Bank of Iran,» Procedia Computer Science, no. 124, pp. 300-310, 2017. https://doi.org/10.1016/j.procs.2017.12.159.

[43] N. Donthu, «Innovation, knowledge, judgment, and decision-making as virtuous cycles,» Journal of Business Research, no. 88, pp. 278-281, 2018.

[44] M. Wang, M. Zheng, L. Tian, Z. Qiu \& X. Li, «A full life cycle nuclear knowledge management framework based on digital system,» Annals 
of Nuclear Energy, no 108, pp. 386-393, 2017. https://doi.org/10.1016/j.anucene.2017.04.047.

[45] Y.-F. Hu, J.-L. Hou \& C.-F. Chien, «A UNISON framework for knowledge management of university-industry collaboration and an illustration,» Computers \& Industrial Engineering, no. 129, pp. 31-43, 2019. https://doi.org/10.1016/j.cie.2018.12.072.

[46] D. Sensuse, E. Cahyaningsih \& W. Wibowo, «Knowledge Management: Organizational Culture in Indonesian Government Human Capital Management,» Procedia Computer Science, no 72, pp. 485-494, 2015. https://doi.org/10.1016/j.procs.2015.12.130. 